
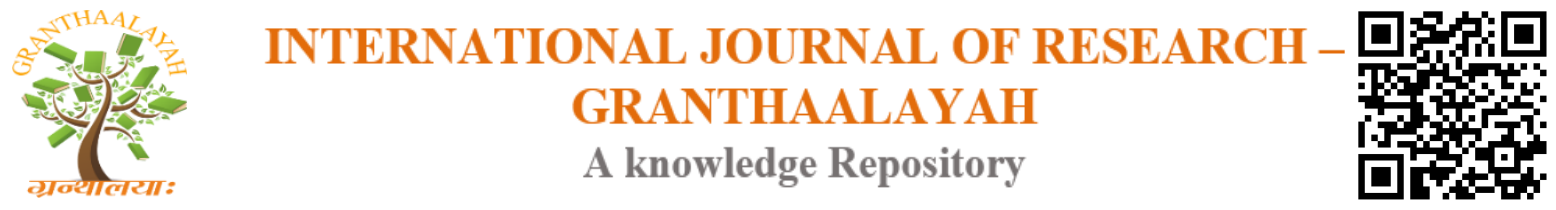

Management

\title{
A SOCIAL-CAPITALIST VIEW ON CORPORATE GOVERNANCE A NEW POST-MODERN PERSPECTIVE
}

\author{
Amos Avny *1 \\ ${ }^{*}$ Senior Management and Strategic Consultant, Omnidev International, Israel
}

\begin{abstract}
After defining the issue, the essay explores some aspects of the current Corporate Governance: Weaknesses of traditional Corporations, containing: 1. Lack of vision and goals, 2. TooFormalistic Management Style, 3. Minimal care for Social Affairs, and 4. Doubtful stands on Environment Protection. Further, desired characteristics of future corporation are detailed: 1. Adopting updated and advanced Managing Methods, 2. Endorsing Capital-Labor balanced relations, 3. Improving Compliance with Food \& Health demands and 4. Enacting updated Command and Control practices. Finally, some of the implementation problems are discussed. In general, the Author points out that the meaningful transformation of the 21st Century - the move from the Modern to the Post-modern Order - also forces the Corporate Governance to change. It should be upgraded from the former, formal setup, responsible only to its shareholders into a much more transparent and trustful system, responsible to a broader body of stakeholders. As faster such a transformation will be, so better and more fruitful it will be, for the corporation and its owners.
\end{abstract}

Keywords: Corporate Governance; Strategy; Post-Modern.

Cite This Article: Amos Avny. (2019). "A SOCIAL-CAPITALIST VIEW ON CORPORATE GOVERNANCE A NEW POST-MODERN PERSPECTIVE." International Journal of Research - Granthaalayah, 7(4), 329-337. 10.29121/granthaalayah.v7.i4.2019.915.

\section{Introduction}

\author{
"A very smart person learns from his neighbors' experience \\ A smart person learns from his own experience \\ A not-so-smart person does not learn, neither from his own nor from his neighbors' \\ experience."
}

(An old Chinese proverb)

Corporate Governance became an important issue due to two major developments, first, "highprofile collapses of a number of large corporations during 2001-2002, most of which involved accounting fraud; and then again after the recent financial crisis in 2008" (Wikipedia). Enron \& MCI in US and Parmalat in Italy, for example. 
The second reason is the falling of public trust and confidence in the corporations' integrity, accountability and credibility.

These two occurrences well represent the move from the $20^{\text {th }}$ Century Modern Era to the $21^{\text {st }}$ Century Post-modern one. They also demonstrate the change from the pure Capitalist perspective, which claims that corporations belong to their stockholder only, to the new reality, promoted by the Social-Capitalist idea that promotes and argues for upgrading stakeholders ${ }^{\mathbf{1}}$ responsibility.

Such a change of mind is crucial for the corporations' wellbeing, and for the interests of its stakeholders. Having so many factors involved in the corporate's life imposes changing the current state, where only few executives really know what is going on. Time comes to establish an upgraded command and control system that will meet the requirements of all the Stakeholders.

After identifying the issue, the essay examines the corporation's weaknesses and discusses the desired Corporate Governance. Further the implementation issue is discussed and finally it ends with conclusions.

\section{Defining the Issue}

For ensuring a common language and a fair understanding of the subject-matter, it is helpful to create a basic platform upon which all will agree. A good departing port may be the dictionary's definition that seems to satisfy everyone.

"Corporate governance refers to the mechanisms, processes and relations by which corporations are controlled and directed. Corporate governance includes the processes through which corporations' objectives are set and pursued in the context of the social, regulatory and market environment. Governance mechanisms include monitoring the actions, policies, practices, and decisions of corporations, their agents, and affected stakeholders. These Governance structures and principles identify and arrange the distribution of rights and responsibilities among different participants in the corporation" (Wikipedia).

At the $21^{\text {st }}$ Century many stakeholders are involved and are taking part in the corporation activities. These stakeholders are among others, Members of the Board of Directors, Chief Executives and Managers, Shareholders, Bankers, Financiers and Creditors. In addition to them come the Corporate's Employees, Customers, Suppliers and other professionals that assist the corporation as auditors, regulators etc.

At these opening lines we can identify the first characteristic that distinct the 21st Century's corporation from its former 20th Century's one. The difference lays with the large number of Stakeholders today, versus the limited number of the Shareholders in the past.

At present, much more entities (Stakeholders) legitimately, are involved in the corporation's business. In addition to the pure and exclusive economic considerations, which steered former

\footnotetext{
${ }^{1}$ Here is the place to note that whereas Shareholders are the direct owners of a firm, its Stakeholders represent a much larger number of bodies, which are interested in the firm' business, like Employees, Customers, suppliers etc.
} 
corporations' Board of Directors, the Post-modern era's corporation's Board has a much broader range of interests, which will later be discussed.

\section{Weaknesses of Traditional Corporations}

Although Modern Corporation was an advanced business structure at its time, like many other classical arrangements, it failed to match the rapid transformations over time. Further, some improvements and updating initiatives are detailed.

\subsection{Corporations' Lack of Vision and Goals}

All traditional Academic Schools of Economics and Business Administration teach, for over hundred years, that the ultimate goal of every economic or business operation is: To maximize the Revenues or profits for its owners - the Shareholders. This goal, although not mentioned in the Bible or the ancient Greek Philosopher's legacy, was introduced with the Capitalism's growth and expansion and became its exclusive assignment.

Advanced Management Theories ${ }^{2}$ teach that every organization, Public or Private ones, for business, a Non-Governmental-Organization (NGO) or not-for-profit associations, must have a vision. These former perspectives guided Executives to concentrate on their narrow-defined mode of operations.

Emphasizing the money making and profits maximizing philosophies was further intensified at the last quarter of the $20^{\text {th }}$ Century. The leader of this school and its main supporter, was the Chicago's Neo-Liberal School of Economics. This trend was also encouraged by developing the new computer's-oriented econometrics techniques. As a technical spirit-less theoretical instrument it only allows the use of one simple goal equation. Such a constraint as having only a single simple goal, which almost does not occur in life, made all the calculations easier and faster. In this case, like others in history, the mathematicians' practical comfort and the economists' narrow perspective promote a calculating method that not always matches reality. Human Corporations, of any type, even if or when it produces only one product or service, cannot concentrate only on one and narrow economic aspect. It acts and lives within a given social and natural environment and is oblige to take it into consideration.

\subsection{Corporations' Too-Formalistic Management Style}

Following the teaching of the "Scientific Management" school and the comfort of the wellestablished Corporations' owners, simple straight-line management modes were installed and used in many former corporations. The best-known example, is the "Assembly Line Technique" installed in the Automobile industry by Henry Ford almost 100 years back. The classical management theories were not attuned to modern life complexity and therefore did not prepare more flexible management recommendations. Those who have (corporations' owners) did not really cared about those who have little or even none. Another example, demonstrating the narrow perspective of the early corporates' owners was the story about the Baby Ford color. In the beginning of the century Henry Ford wish to build a popular car and called it Baby Ford.

${ }^{2}$ See for example: Collins C. James \& Porras I. Jerry, 1994 
When discussing its color, Ford decided that it should be black only. He denied his marketing experts and claimed that he knows better than any automobile customer's preference. So, all the cars of this series were colored black, but only few were sold. The demand that is determined by the customers overcame Ford's narrow perspective.

There are many other cases that teaches the same thing. Corporates' owners or executives fail to understand that sometimes ordinary customers, with little experience and less money, affect and determine more the life of their corporation. Some fifty years or more were needed for corporates' owners to understand the leading successfully an organization is more complicated than acting simply by the rules or following the pure engineering directions. Corporate Governance is similar to administrating a human organization and therefore it should be involved in its social surroundings.

Another example of formal relations in management was demonstrating by theories and practices of job description. The prevailing mode was to draw a model of the organization's layout and to give every position in the scheme a definite place. Later, the different candidates were guided to meet the demands of the relevant position. In the beginning, this practice was introduced in order to make management more professional and to prevent incompetent kin's or friends' nomination. The advocators of this technique gave priority to managers with remarkable credentials. Although in its time this method had many advantages, later over time it does not meet the more advanced corporations. For today's chaotic world other, more flexible, open-minded and imaginative managers are required.

\subsection{Corporations' Minimal Care for Social Affairs}

All together the business world of the first half of the $20^{\text {th }}$ Century distanced itself from almost all the communal and social affairs of its time. This natural tendency of the capital-owners was encouraged by many in the Academy. The conventional wisdom of that time claimed for maintaining a distinct and clear separation between the public social sector and the business private sector. For business-oriented corporations was it quite easy and positive to follow such an academic recommendation.

\subsection{Corporations' Stand on Environment Protection}

For many years, environment protection's issues did not worry business organizations and corporations' Boards in particular. These issues were the business of some idealist Academicians and some environment and social activists, but never bothered economists and business persons. Only at the last quarter of the $20^{\text {th }}$ Century and the growing concerns of the International Civic communities they became part of the global agenda. At present, it is clear to almost every entrepreneur and every Board of Directors that their old and new enterprises must firmly comply with the limitations, the rules and the instructions of the environment protection agencies. This compliance is stronger than any of the Directors' gestures and is mandatory to all giant industries, like the automobile, food and drugs manufacturers. 


\section{The Desired Corporate Governance}

Like other fields of management, Corporate Governance, experts and owners, must adopt the new spirits that prevail today. They have to honestly absorb and grasp the present new reality that they are not the only and the exclusive power that drives and directs the corporation. This is a very meaningful change, it is mostly and first of all, a psychological mind-set transformation. It is mainly an emotional rather than logical change-of-mind. This transformation also gives a new, different and a more updated meaning to two of the most popular terms of the "Free- market" Economic axioms -"the Market powers," ${ }^{3}$ and the Market Invisible hands." ${ }^{4}$ The new reality indicates, in contrary to many Capitalists' wish that there are neither anonymous powers nor invisible hands in the Market. Markets are not an abstract term representing a grandiose idea. Markets, almost all of them, reflect, like politics, concrete demands and preferences of real people.

Corporations owners, Board of Directors' members, Chief Executives and Investment Bankers must realize that today, every enterprise has many stakeholders, much more than the former classical stockowners. Being apart from the Marxist ideology of "Nationalism" and with no legalistic necessity, actual facts of life force properties and capital owners to share their assets with the growing numbers of stakeholders. This seems to be the real meaning of the $21^{\text {st }}$ Century business transformation.

A gradual evolution of the prevailing political-economic conditions deletes in practice and removes the justifications for Marx's calling for "nationalization of the production means." In the $21^{\text {st }}$ Century the customer's influence on the Firm's future is not smaller than its original owner. Thus, "Political Nationalization" is obsolete and not relevant any more.

One does not have to be neither a partner nor a shareholder in order to affect the corporation behavior. He or she can be just a leader of a large community and by that to significantly determine the firm future. In addition to business and economic concerns, social and political considerations affect meaningfully corporations' behavior. Thus, knowledge, connections and expertise of these area are indispensable part required from Corporations' Executives.

The present communication supper giants and the social networks that were raised around them are another fascinating example of the humongous and extraordinary power of nowadays general public. They clearly demonstrate the situation where in an affluent society (and in a Byers' Market) 1 the customers have very much influence on the firm future, not less than its Board.

The first step for a Corporation to found a competent Governance is to establish a more competent Board of Directors containing open-minded, innovative, forward-looking and inspiring Members. Such an advanced Board should also contain first-rate relevant Specialists, Strategists and goal-setters and Control, Command and Report Experts. These requirements were summed up

\footnotetext{
3 "market power is the ability of a firm to profitably raise the market price of a good or service over marginal cost" Wikipedia). It is also known as "Sellers' Market."

4 "The invisible hand is a term used by Adam Smith to describe the unintended social benefits of individual actions. The phrase was employed by Smith with respect to income distribution (1759) and production (1776). The exact phrase is used just three times in Smith's writings" (Wikipedia).
} 
by the similar study by Grant Thornton reviewed 1865 Executives, in 36 countries. ${ }^{5}$ The review points out on four major points to be updated by the Corporations' Board:

1) Installing a culture of Integrity and Transparency

2) Creating a challenging and heterogeneous atmosphere

3) Building a basis of relevant and competent experts

4) Balancing the requirements of short- \& long-term strategies.

After installing and enacting the above strategies the Corporations' Board should proceed for ensuring the operating of the other following actions.

\subsection{Adopting Updated \& Advanced Managing Methods}

Once, Corporations owners and Executives adopt the new actual reality (Cars buyers rather than Henry Ford are those who determine the color of their cars) the corporations are ripe for enabling the reshaping process. As said, the first step was a psychological one. The second step should be functional - encouraging and enacting some actions. In general, many of the managing and administrative previous rigid procedures must be revised and updated for matching the spirit of the new era. Since now appeared many new stakeholders Corporation's governance should be reshaped to meet their interests. Advanced Marketing Methods, Customers Relation Departments and Imaginative Sale Techniques should be immediately installed.

A more flexible, in-house communication linkages should be enacted for enabling better and faster connections between all the corporation's levels. In-house entrepreneurs, innovative initiators and quality-oriented experts should be encouraged to propose their improvements. As the Corporation now, almost belongs to many, every stakeholder should be involved in the process of developing its products and upgrading its performance.

\subsection{Endorsing Capital-Labor Balanced Relations}

Capital-Labor linkage traditionally was the house of many bad spirits and the nest of continual conflicts. Whether organized or non-organized labor, the employee's interests are among the basic corner-stones of every organization. An Atmosphere of mutual trust, a search of collaboration between Capital and Labor, a tradition of synergy and common interest and a mutual mode of cooperation can significantly up-grade the corporation's performance. Every smart director, executive or manger, who will choose this option will contribute to the organization much more than a rigid, narrow-minded, honor-seeker and stiffed individual.

Promoting the wellbeing of a corporation today is the interest of its stakeholders so all of them should work together for achieving this goal.

\footnotetext{
${ }^{5}$ Grant Thornton is the world's seventh largest professional services network ${ }^{[1]}$ of independent accounting and consulting member firms which provide assurance, tax and advisory services to privately held businesses, public interest entities, and public sector entities"(Wikipedia).
} 


\subsection{Improving Compliance with Food \& Health Demands}

This is almost the most updated demand required from a business organization. Our fathers and forefathers would have never dream that such a requirement will ever appear. It is presented here because it clearly demonstrated todays' business transformation, which also affects Corporation's Governments. It is clear to everyone that the previous practice of sifting to less-developed and poor countries or areas, outdated foods and expired drugs is going to stop. Neither an institution nor public opinion will allow the continuation of such popular policy. A proper Corporation Governance must be attuned to such demands and it has to comply firmly with similar demands. It does not matter whether these are rationale or logical demands. As long as they are general or popular demands, business and non-business enterprises must meet them. Corporations' Governments are not designated to teach the general public or to educate the customers. Their mission is just to satisfy their customers' demands. This maybe is the Post-modern interpretation to the former classic economic term "the market powers." The market is no more an anonymous powerful entity. It is, rather, a concrete focused people's demand. When Corporation Governance is measured by its rate of meeting the public demands, advanced tools and techniques must be employed for fulfilling this undertaking.

\subsection{Enacting Updated Command \& Control Practices}

This maybe, is the crucial and key function that must be reshaped in order to upgrade the corporation governance and make it congruent with the $21^{\text {st }}$ post-modern requirements. When so many direct stakeholders are involved and many other interest groups are affected, the internal report and control functions must be upgraded and reconstructed for meeting the public demand. The first point here is the Trust issue. It is quite easy to brake or destroy Trust. However, years may pass until a new one is reconstructed. Years of efforts and tons of sweat could be demolished by an irresponsible behavior or a careless act of a corporation's pretentious executive.

Failing in attaining the above goals can rapidly be seen on the balance-sheet figures and a meaningful decrease of corporate's "market's share" and its shares' value.

\section{Implementation}

The British taught us that "the taste of the pudding is determined by the eaters", similarly, "the value of a great idea is determined by its actual implementation". An idea or an opinion that do not evoke some kind of activity, either additional research or implementation attempts, are eventually very little. This issue becomes more complicated when it refers to existing organizations and particularly when it deals with large establishments like Corporations. Since our paper deals with running enterprises the implementation is much more difficult. Many hurdles stand in the execution way, some relate to individuals and some are connected with interest groups. However, all are related to human beings.

The Corporation's current establishment has many vested interests, which most of them prefer continuation of the existing structure. The existing structure is known by and serves most of the managing staff. The fact that it is not so efficient, the cases that some marginal people are suffering and the events where the given service do not meet the needs do not worry too much the middle range managers. They want to keep in their hands the power and the ability to make the decision 
that match their views. On the other hand, Board members and Executives, frequently are concentrated mostly on the financial results, the Balance-sheet data and the stock market numbers. They tend to disregard all the other aspects.

Unfortunately, most corporations' directors in the past did not care too much about the social and the environment stands of their Corporation.

It seems therefore, that implementing a meaningful change in Corporation Governance will take time, another 5 to 10 years. In this regard the time period required for reforming a business entity, is half at least, from the required for introducing a similar reform into a public enterprise. The reason for such a difference arises from lack of "Change Agents". In a business organization the Board of Directors and the Executives act as "Change Agents" who force the organization to change and improve its performance. Unfortunately, in government and other public organizations usually there are no "Change Agents". Very few official really think that something should be better.

Whereas, the best way for introducing an improving change into public organizations is through public opinion, the proper way for doing it in business entities, like corporations, is by the Balance-sheet results. However, in both cases, the Academy, and especially, open minded and far looking bright Professors and Students, are the ones that should start such a move. Since improving or updating organizations are tiresome and a lasting process it is good that those who endorse it will start them as young students. Because when they will complete the processes these students will receive their professorship.

\section{Conclusions}

Corporate Governance, like many other organizations must make some transformation in order to meet todays' demands. It is almost clear that when the external environment is changing all the bodies that exist within this chaotic sphere must change and upgrade their internal functions and cannot leave them untouched. The author claims that although Corporate Governance deals mainly with business and economic matters, the recommended transformation refers to three areas that construct the Post-modern advanced, Democracies. The rationale for this approach is driven from the contemporary reality where the former clear distinction, between the assets' owners and the users of their products, was firmly maintained. The common wisdom of today teaches that organizations and corporations in particular, is foremost responsible to their stakeholders, rather than their shareholders.

Thus, Corporate Governance must meet a wide range of desires in three major areas: Economic, Society and Environment. The corporate's vision and goals must reflect these undertakings. However, Corporate governance and its agencies must be reorganized so that they will match the Post-modern requirements. For attaining these goals Corporations should adopt the following strategies:
a. Adopting updated and upgraded management techniques
b. Enacting a more flexible and considering bureaucracy
c. Imposing a transparent and open communication modes
d. Ensuring compliance with the Food, Drugs \& Environment rules 
e. Endorsing Capital-Labor fair and balanced relations.

In sum, it is fair reminding everybody that at present, corporate governance's mission, is to execute and run its businesses, with the people, by the people and for the people.

\section{References}

[1] Avny Amos 2016, Essays of a Senior Optimist, Germany, Saarbruken: LAP LAMBERT

[2] Avny Amos, 2012, How to secure the Blessing of Liberty - a Social-Capitalism Manifest, Germany, Saarbruken: LAP LAMBERT

[3] Collins C. James (2001, Good to Great, (Heb. Ed.), Tel Aviv: Pecker Pub.

[4] Collins C. James \& Porras I J. (1994) Built to Last, (Heb. Ed) Tel Aviv: Pecker Pub

\footnotetext{
*Corresponding author.

E-mail address: amosav@ smile.net.il
} 